\title{
A 30-Year-Old Man with Acute Motor Axonal Neuropathy Subtype of Guillain-Barré Syndrome Having Hepatitis A Virus Infection
}

\author{
Alireza Samadi ${ }^{1}$, Fariborz Mansour-Ghanaei ${ }^{1, *}$, Farahnaz Joukar ${ }^{2}$, \\ Sara Mavaddati ${ }^{1}$, Iman Sufi Afshar ${ }^{1}$
}

\begin{abstract}
1. Gastrointestinal and Liver Diseases Research Center, Guilan University of Medical Sciences, Rasht, Iran

2. Caspian Digestive Diseases Research Center, Guilan University of Medical Sciences, Rasht, Iran
\end{abstract}

\section{* Corresponding Author:}

Fariborz Mansour-Ghanaei, MD, AGAF Professor of Gastroenterology Gastrointestinal and Liver Diseases Research Center (GLDRC), Guilan University of Medical Sciences, Razi Hospital, Sardar-Jangle Ave., P.O. Box: 41448-95655, Rasht, Iran

Tel: +9833535116

Fax: +9833534951

Email: ghanaei@gums.ac.ir

Received: 26 Sep. 2018

Accepted: 18 Feb. 2019

\section{ABSTRACT}

Guillain-Barré syndrome (GBS) is an acute monophasic immune-mediated polyradiculoneuropathy. Here, we report a case of a young man with acute motor axonal neuropathy (AMAN) subtype of GBS having hepatitis A virus (HAV) infection.

A 30-year-old man with icterus was referred to emergency center of Razi Hospital. He complained of flu-like symptoms 10 days before the onset of icterus. Also, he suffered from gradual fatigue and weakness with dark urine. He experienced neurological symptoms of muscle paralysis (ascending from the legs to hands). Neurological consultant suspected GBS at the first step based on clinical examinations. He was candidate for five sessions of plasmapheresis. The ultrasonography revealed liver span $166 \mathrm{~mm}$, which was greater than the normal range, with normal parenchymal echo. The gallbladder wall was thicker than normal and gallstone with lesion was not seen in different conditions. He was discharged after total improvement of neurological symptoms and muscular power. In addition, the results of International normalized ratio (INR), partial thromboplastin time (PTT), prothrombin time (PT), alkaline phosphatase (ALK), alanine aminotransferase (ALT), aspartate aminotransferase (AST), bilirubin total and direct (Bil T, D) tests were normal after 2-month follow-up.

Although, acute viral infections such as hepatitis E virus (HEV) is common in patients with GBS; the possibility of HAV infection in patients with its risk factor should not be neglected.

\section{KEYWORDS:}

Guillain-Barré syndrome, Hepatitis A, Nervous System Diseases

Please cite this paper as:

Samadi AR, Mansour-Ghanaei F, Joukar F, Mavaddati S, Sufi Afshar I. A 30-Year-Old Man with Acute Motor Axonal Neuropathy Subtype of Guillain-Barré Syndrome Having Hepatitis A Virus Infection. Middle East J Dig Dis 2019:11:110-115. doi: 10.15171/mejdd.2018.136.

\section{INTRODUCTION}

Guillain-Barré syndrome (GBS) is an acute monophasic immunemediated polyradiculoneuropathy. ${ }^{1}$ However its precise molecular pathogenesis and variants are uncertain. ${ }^{2}$ Although GBS may occur among all ages, its mean age of onset is reported differently. It affects male slightly more than female patients. ${ }^{1,3,4}$ Also, the worldwide incidence of GBS varies broadly. ${ }^{5,6}$ The overall incidence of GBS in children is lower than adults. ${ }^{7}$ There are several types of GB including acute inflammatory demyelinating polyradiculoneuropathy (AIDP); axonal forms of GBS, such as acute motor-sensory axonal neuropathy (AMSAN) and acute motor axonal neuropathy (AMAN); and miller 
Table 1: Blood test report

\begin{tabular}{|c|c|}
\hline White blood cell (WBC): $7.3 \times 103 / \mathrm{UL}(4-10 \times 103 / \mathrm{UL})$ & Creatinine $(\mathrm{Cr}): 0.78(0.8-1.3 \mathrm{mg} / \mathrm{dL})$ \\
\hline Hemoglobin (HB): 15.4 (13-17.5 g/dL ) & Blood urea nitrogen (BUN): $16(7-20 \mathrm{mg} / \mathrm{dL})$ \\
\hline Mean corpuscular volume (MCV): 85.2 (80-100 FL) & Estimated glomerular filtration rate (eGFR): $87(>60 \mathrm{nmol} / 24 \mathrm{~h})$ \\
\hline Mean corpuscular hemoglobin concentration (MCHC): 33.7 (31-37 gr/dL) & Total protein (Total Pr): 8 (6.6-8.8 gr/dL) \\
\hline Platelet (PLT): $245 \times 103 / \mathrm{UL}(150-450 \times 103 / \mathrm{UL})$ & Lipase: 34 (0-160 U/L) \\
\hline Ferritin: $610(12-300 \mathrm{ng} / \mathrm{mL})$ & Lactate dehydrogenase (LDH): 341 (100-190 U/L) \\
\hline Albumin (Alb): $4.5(3.5-5 \mathrm{~g} / \mathrm{dL})$ & Bilirubin total $($ Bill T): $27(0-1.1 \mathrm{mg} / \mathrm{dL})$ \\
\hline Potassium (K): 4 (3.5-5.3 mEg/L) & Bilirubin direct (Bill D): $16.4(0-0.7 \mathrm{mg} / \mathrm{dL})$ \\
\hline Sodium $(\mathrm{Na}): 134(135-145 \mathrm{mEg} / \mathrm{L})$ & Aspartate aminotransferase (AST): $628(<40$ IU/L) \\
\hline Calcium $(\mathrm{Ca}): 9.6(8.5-10.5 \mathrm{mg} / \mathrm{dL})$ & alanine aminotransferase (ALT): $127(<40 \mathrm{IU} / \mathrm{L})$ \\
\hline Phosphorus (P): $3.2(2.5-4.5 \mathrm{mg} / \mathrm{dL})$ & Alkaline Phosphatase (Alk p): 298 (64-306 IU/L) \\
\hline Magnesium (Mg): 2.5 (1.7- $2.2 \mathrm{mg} / \mathrm{dL})$ & Creatine phosphokinase (CPK): 36 (24-195 U/L) \\
\hline Erythrocyte sedimentation rate (ESR): $21(0-22 \mathrm{~mm} / \mathrm{hr})$ & Iron $(\mathrm{Fe}): 64(13.5-17.5 \mathrm{~g} / \mathrm{dL})$ \\
\hline C-reactive protein $(\mathrm{CRP}): 14(<6 \mathrm{mg} / \mathrm{L})$ & Total iron-binding capacity (TIBC): 131 (240-450 mcg/dL) \\
\hline
\end{tabular}

Table 2: The urine analysis

\begin{tabular}{ll}
\hline ketone: negative & bilirubin: negative \\
\hline blood: negative & urobilinogen: $1+$ \\
\hline White blood cell (WBC): 2-3 & color: orange \\
\hline RED blood cell (RBC): 1-2 & appearance: clear \\
\hline bacteria: rare & PH: 6.8 \\
\hline nitrite: negative & urine protein: trace \\
\hline crystal ca-oxalate: many & Glucose: negative \\
\hline
\end{tabular}

fisher syndrome (MFS), which has been reported that there is a possible association between MFS, thromboembolic disease, and angioedema. ${ }^{8-10}$ In addition, one of its rare variant consists of facial diplegia and paresthesia, which can make the diagnosis difficult. ${ }^{11}$ Although autonomic dysfunction is a known but rare presentation of GBS that should be considered in the differential diagnosis in patients with refractory bradycardia and hypotension, ${ }^{12}$ it is stated to be preceded by a non-specific infection of variable type, usually a few weeks before the onset of neurological symptoms. Meanwhile trauma, surgery, or vaccination would be as triggering factors. ${ }^{13}$ Here, we report a case of a young man with AMAN subtype of GBS having hepatitis A virus (HAV) infection.

\section{CASE REPORT}

A 30-year-old man with icterus was referred to emergency center of Razi Hospital. There was no history of disease, smoking, or drug abuse. He stated to have flu-like symptoms 10 days before the onset of icterus, which was treated as an outpatient. Also, he suffered from gradual fatigue and weakness with dark urine. Then he was referred to the Department of Gastrointestinal and Liver Diseases of Razi Hospital for admission. In addition, the patient declared nausea, fever, and chills, which had improved over the previous 2 days, while the icterus still remained. There was no history of disease among him and his family. He reported a history of appendectomy 15 years earlier. His initial blood test showed high levels of liver function enzymes, hyperbilirubinemia as well as high C-reactive protein (CRP) (table1). Also, table 2 shows the results of urine analysis.

On the second day of admission, he experienced neurological symptoms of muscle paralysis (ascending from the legs to hands). Neurological consultant suspected GBS based on clinical examinations. The patient was scheduled for five sessions of plasmapheresis for the first step because in any situations of GBS suspicion, treatment is vital.

According to the imaging evaluations such as ultrasonography, the liver span was $166 \mathrm{~mm}$, which was greater than the normal range, with normal parenchymal echo. Intra- and extrahepatic bile ducts were normal. The gallbladder wall was thicker than normal and gallstone with lesion was not seen in different locations. 
The specific viral marker tests were ordered due to acute hepatitis (viral or autoimmune) symptoms which showed: hepatitis B surface antigen (HBS $\mathrm{Ag}$ ): negative, hepatitis $\mathrm{C}$ virus antibody ( $\mathrm{HCV}$ $\mathrm{Ab}$ ): negative, epstein-barr virus (EBV) (viral capsid antigen (VCA) [immunoglobulin M (IgM):-, immunoglobulin $\left.\mathrm{G}(\mathrm{IgG}):^{+}\right]$), cytomegalovirus (CMV): negative, herpes simplex virus (HSV) (IgG): positive, serum HAV (IgM): positive, anti hepatitis E virus(HEV)( IgM): negative, anti HEV (IgG): negative, gamma: $1.7(0.6-1.5 \mathrm{~g} / \mathrm{dL})$, beta: $0.9(0.5-1.2 \mathrm{~g} / \mathrm{dL})$, alpha2: $0.8(0.6-1.1 \mathrm{~g} / \mathrm{dL})$, alpha 1: $0.3(0.1-0.2 \mathrm{~g} / \mathrm{dL})$, albumin: $3.8(3.2-5.3 \mathrm{~g} / \mathrm{dL})$ with detection of IgM \& Kappon \& lambdco light chains bands in serum immune fixation report. Antinuclear antibody (ANA): negative, anti-smooth muscle antibody (ASMA): negative.

In addition, during neurological consultation, the suspicion to GBS and vasculitis led to proper further laboratory tests, which showed the following results: anti-double stranded DNA (anti-dsDNA): $3.2(<25$ $\mathrm{U} / \mathrm{mL}$ ), C. Proteinase 3 (PR3) anti-neutrophil cytoplasmic antibody (ANCA) (PR3-ANCA): $<3(<12$ $\mathrm{Au} / \mathrm{mL}$ ), Perinuclear ANCA (P-ANCA) [anti- myeloperoxidase (anti MPO)]: $3.7(<12 \mathrm{Au} / \mathrm{mL})$, anti-mitochondrial $\mathrm{Ab}$ (AMA): negative, lupus anticoagulant (LAC): negative and, anti-liver-kidney-microsome antibody (LKMA): 3.1 $(<12 \mathrm{Au} / \mathrm{mL})$.

These findings made the possibility of GBS stronger rather vasculitis. After completion of plasmapheresis sessions, the neurological abilities and muscular power of the patient improved completely. Also, the diagnosis of AMAN subtype of GBS was confirmed based on the electromyogram (EMG)/nerve conduction velocity (NCV) findings, which were performed during the plasmapheresis (table 3). The patient was discharged from the Gastroenterology and Neurology Department. After 2-month follow-up, the results of International normalized ratio (INR), partial thromboplastin time (PTT), prothrombin time (PT), alkaline phosphatase (ALK), alanine aminotransferase (ALT), aspartate aminotransferase (AST), bilirubin total and direct (Bil T, D) tests were normal.

\section{DISCUSSION}

Viral hepatitis has rare complications such as GBS, auditory neuritis, seizures, and mononeuritis. The frequent association between GBS and hepatotropic viruses including cytomegalovirus, acute viral hepatitis B (HB), acute hepatitis C, hepatitis D, hepatitis E (HE), and rarely with hepatitis A (HA) has been reported. ${ }^{14,15}$ Also, several neurological complications are in association with viral HA such as transverse myelitis, myeloradiculopathy, mononeuropathy, and mononeuritis, which have immune pathogenesis bases. ${ }^{16}$ Furthermore, a variety of neurological syndromes including GBS have been reported in serologically confirmed hepatitis A.${ }^{17,18}$ The pathogenesis of HA virus-associated GBS is unknown. It is stated that there should be a molecular resemblance between hepatotropic viruses' antigens such as HA and the components of myelin in the peripheral nerves. ${ }^{14}$ While it is required to conduct precise epidemiological evaluations to distinguish the relationship between HA viral infection and GBS, it is suggested that this type of infection has a molecular mimicry as shares cross reactive epitopes, which in turn cross reacts with Schwann cells, myelin, or other peripheral nerve antigens. ${ }^{19}$ However these possibilities require further explorations..$^{20}$ It has been revealed that GBS following HAV is male dominant, occurs in younger ages, and its overall prognosis is better unlike other infections such as C. Jejuni. ${ }^{21}$ Meanwhile, there is no relationship between the severity of neurological symptoms and the fulminant hepatitis, which is not common among the patients. The clinical features of GBS following HA is summarized as follows: I) less than 14 days interval between the onset of hepatitis and the development of neuropathic symptoms, II) frequent association with facial nerve palsy, III) frequent impairment of joint position and vibratory sense along with superficial sensation, and IV) appropriate outcome of the neuropathic symptoms, which is independent of ALT level associated with liver dysfunction severity. ${ }^{22}$ In addition, one of the GBS subtypes characterized by pure motor involvement and absence of evidence of demyelination in electrophysiological tests is AMAN, ${ }^{23}$ which is linked to Campylobacter jejuni and Zika virus infection based on the available literature..$^{24,25}$ There is no certain report about the AMAN frequency, which is claimed to be a consequence of variability in infectious agents 
Table 3: The EMG and NCV findings that are compatible with mild acute motor axonal neuropathy

\begin{tabular}{|c|c|c|c|c|c|c|c|c|}
\hline \multicolumn{9}{|c|}{ NERVE CONDUCTION STUDIES } \\
\hline & AMP. & LATENCY & \multicolumn{2}{|c|}{ NCV } & \multicolumn{4}{|c|}{ F WAVE LATENCY } \\
\hline R. MEDIAN MOTOR & 4.7 & 3.2 & \multicolumn{2}{|c|}{53} & \multicolumn{4}{|c|}{28} \\
\hline R. ULNAR MOTOR & 5.4 & 2.5 & \multicolumn{2}{|c|}{55} & \multicolumn{4}{|c|}{26} \\
\hline L. MEDIAN MOTOR & 3.9 & 3.5 & \multicolumn{2}{|c|}{53} & \multicolumn{4}{|c|}{25} \\
\hline L. ULNAR MOTOR & 4.9 & 2.9 & \multicolumn{2}{|c|}{55.1} & \multicolumn{4}{|c|}{26} \\
\hline R. MEDIAN SENSORY & 22 & 3.4 & & & & & & \\
\hline R. ULNAR SENSORY & 19 & 2.7 & & & & & & \\
\hline L. MEDIAN SENSORY & 27 & 2.8 & & & & & & \\
\hline L. ULNAR SENSORY & 26 & 3.4 & & & & & & \\
\hline R. RADICAL SENSORY & 12 & 2.3 & & & & & & \\
\hline \multicolumn{9}{|l|}{ R. SAPHENOUS SENSORY } \\
\hline R. D. PERONEAL. M & 2.45 & 5.23 & \multicolumn{2}{|c|}{36} & \multicolumn{4}{|c|}{ ABSENT } \\
\hline R. POS. TIBIAL. M & 3.67 & 5.3 & \multicolumn{2}{|c|}{36} & \multicolumn{4}{|c|}{ ABSENT } \\
\hline L. D. PERONEAL. M & 2.34 & 5.7 & \multicolumn{2}{|c|}{38} & \multicolumn{4}{|c|}{ ABSENT } \\
\hline L. POS. TIBIAL M & 4.3 & 6.2 & \multicolumn{2}{|c|}{35} & \multicolumn{4}{|c|}{ ABSENT } \\
\hline R. S.P.N SENSORY & \multicolumn{4}{|l|}{5.7} & & & & \\
\hline L. S.P.N SENSORY & \multicolumn{4}{|l|}{4.87} & & & & \\
\hline R. SURAL. SENSORY & \multicolumn{4}{|l|}{6.7} & & & & \\
\hline L. SURAL. SENSORY & \multicolumn{4}{|l|}{5.9} & & & & \\
\hline R. H REFLEX & \multicolumn{4}{|l|}{33} & & & & \\
\hline L. H REFLEX & \multicolumn{4}{|l|}{34} & & & & \\
\hline \multicolumn{9}{|c|}{ EMG } \\
\hline \multirow{2}{*}{ MUSCLE } & & INSER. & FIB. & & & OLUNTA & Y M.U.A.P & \\
\hline & ROOT & ACT. & P.SW & FASCI & dur. recu.pat & amp & polyph & activation \\
\hline R. TRICEPS & $\mathrm{C} 6,7,8$ & Normal & Normal & Normal & Normal & Normal & Normal & Full \\
\hline L. TRICEPS & $\mathrm{C} 6,7,8$ & Normal & Normal & Normal & Normal & Normal & Normal & Full \\
\hline R. EDC & $\mathrm{C} 7,8$ & Normal & Normal & Normal & Normal & Normal & Normal & DEC \\
\hline R. FDI & $\mathrm{C} 8, \mathrm{~T} 1$ & Normal & Normal & Normal & Normal & Normal & Normal & full \\
\hline R. TIBIALIS ANTERIOR & L4,L5 & Normal & Normal & Normal & Normal & Normal & Normal & DEC \\
\hline L. TIBIALIS ANTERIOR & L4,L5 & Normal & Normal & Normal & Normal & Normal & Normal & DEC \\
\hline R. PERONEUS LONGUS & $\mathrm{L} 5, \mathrm{~S} 1$ & Normal & Normal & Normal & Normal & Normal & Normal & DEC \\
\hline L. PERONEUS LONGUS & $\mathrm{L} 5, \mathrm{~S} 1$ & Normal & Normal & Normal & Normal & Normal & Normal & DEC \\
\hline R. GASTROCNEMIUS & & Normal & Normal & Normal & Normal & Normal & Normal & DEC \\
\hline
\end{tabular}

exposure in different geographical areas. In spite of that, the estimated incidence of AMAN is $30-65 \%$ in Asia and Central and South America. ${ }^{26}$ According to some reports this form of GBS has an incidence from $<10 \%$ of the patients with GBS in Western countries to over $40 \%$ in East Asia where it frequently affects. ${ }^{27-29}$ It is characterized by rapidly progressive weakness, often with respi- ratory failure and usually good recovery, in comparison with other subtypes such as AMSAN, which is generally associated with slow and incomplete recovery. ${ }^{30} \mathrm{Re}$ garding electrodiagnostic studies, most of the cases were compatible with an acquired demyelinating polyradiculoneuropathy, while just a few cases had dominant axonal involvement like AMAN. ${ }^{31,32}$ Also, it has been stated 
that GBS is vastly connected to HE infection rather than HAV infection. ${ }^{33}$ In our case, as the patient did not have the risk factors of $\mathrm{HE}$ such as journey to Pakistan or other endemic areas, pregnancy, and immunodeficiency but had the risk factors of viral HA and HB infection including flu-like symptoms, fever, and icterus, we did not check HE, while his result was positive for serological HAV IgM. Also, in this case there was no facial palsy that is frequent in this subtype of GBS.

\section{CONCLUSION}

Remarkably, considering the accurate type of viral hepatitis infection in patients with different subtypes of GBS in the golden time which has an impressive key role in diminishing the neurological symptoms, we should not correlate and consider all the patients' complaints to the liver disease. Meaningly; it must be considered according to other main related disorders. Although, AMAN subtype of GBS is common with HEV infection, the possibility of HAV infection in cases with its risk factor should not be neglected.

\section{ACKNOWLEDGMENT}

We would like to thank all members of Gastrointestinal \& Liver Diseases Research Center (GLDRC). We also thank the patient for providing consent for this case report.

\section{Informed consent}

Written informed consent was obtained for anonymized patient's information to be published in this article.

Source of financial support: There was no financial support for this report.

\section{ETHICAL APPROVAL}

There is nothing to be declared.

\section{CONFLICT OF INTEREST}

The authors declare no conflict of interest related to this work.

\section{REFERENCES}

1. Dimachkie MM, Barohn RJ. Guillain-Barré syndrome and variants. Neurol Clin 2013;31:491-510. doi:10.1016/j.ncl.2013.01.005.
2. Dalakas MC. Pathogenesis of immune-mediated neuropathies. Biochim Biophys Acta 2015;1852:65866. doi:10.1016/j.bbadis.2014.06.013.

3. Shrivastava M, Nehal S, Seema N. Guillain-Barre syndrome: Demographics, clinical profile \& seasonal variation in a tertiary care centre of central India. Indian J Med Res 2017;145:203. doi:10.4103/ijmr.IJMR 995_14.

4. RochaMSG, Brucki SMD, CarvalhoAAdS, Lima ÚWP. Epidemiologic features of Guillain-Barre syndrome in Sao Paulo, Brazil. Arq Neuropsiquiatr 2004;62:33-7. doi:10.1590/S0004-282X2004000100006.

5. Hughes RA, Rees JH. Clinical and epidemiologic features of Guillain-Barré syndrome. J Infect Dis 1997;176:S92-S8. doi:10.1086/513793.

6. Govoni V, Granieri E. Epidemiology of the GuillainBarré syndrome. Curr Opin Neurol 2001;14:605-13.

7. McGrogan A, Madle GC, Seaman HE, De Vries CS. The epidemiology of Guillain-Barré syndrome worldwide. A systematic literature review. Neuroepidemiology 2009;32:150-63. doi:10.1159/000184748.

8. Salehi N, Choi ED, Garrison RC. A Case of Miller Fisher Syndrome, Thromboembolic Disease, and Angioedema: Association or Coincidence? $\mathrm{Am} \mathrm{J}$ Case Rep 2017;18:52. doi:10.12659/AJCR.901940.

9. Toopchizadeh V, Barzegar M. Electrophysiologic features of childhood Guillain-Barré syndrome in Iran. $J$ Pediatr Neurol 2008;6:11-6. doi:10.1055/s-0035-1557429.

10. Akbayram S, Doğan M, Akgün C, Peker E, Sayın R, Aktar F, et al. Clinical features and prognosis with Guillain-Barré syndrome. Ann Indian Acad Neurol 2011;14:98. doi:10.4103/0972-2327.82793.

11. Nishiguchi S, Branch J, Tsuchiya T, Ito R, Kawada J. Guillain-Barré Syndrome: A Variant Consisting of Facial Diplegia and Paresthesia with Left Facial Hemiplegia Associated with Antibodies to Galactocerebroside and Phosphatidic Acid. Am J Case Rep 2017;18:1048. doi:10.12659/AJCR.904925.

12. Le Dung Ha FA, Rao M. Guillain-Barré Syndrome Presenting with Sinus Node Dysfunction and Refractory Shock. Am J Case Rep 2017;18:251. doi: 10.12659/AJCR.902668.

13. Anlar O, Tombul T, Arslan S, Akdeniz H, Caksen H, Gundem A, et al. Report of five children with GuillainBarré syndrome following a nationwide oral polio vaccine campaign in Turkey. Neurol India 2003;51:544.

14. Jo Y-S, Han S-D, Choi J-Y, Kim IH, Kim Y-D, Na S-J. A case of acute motor and sensory axonal neuropathy following hepatitis a infection. $J$ Korean Med Sci 2013;28:1839-41. doi:10.3346/ jkms.2013.28.12.1839.

15. Oomes P, Van Der Meché F, Kleyweg R. Liver function disturbances in Guillain-Barre syndrome A prospective longitudinal study in 100 patients. Neurology 1996;46:96-100. doi:10.1212/WNL.46.1.96. 
16. Azuri J, Lerman-Sagie T, Mizrahi A, Bujanover Y. Guillain-Barré syndrome following serological evidence of hepatitis A in a child. Eur J Pediatr 1999;158:341-2. doi:10.1007/s004310051086.

17. Tabor E. Guillain-barré syndrome and other neurologic syndromes in hepatitis A, B, and non-A, non-B. J Med Virol 1987;21:207-16. doi: 10.1002/jmv.1890210303.

18. Stübgen J-P. Neuromuscular disorders associated with Hepatitis B vaccination. J Neurol Sci 2010;292:1-4. doi:10.1016/j.jns.2010.02.016.

19. Kadanali A, Kizilkaya M, Tan H, Erol S, Tasyaran MA, Parlak M. An unusual presentation of hepatitis A virus infection: Guillain-syndrome. Trop Doct 2006;36:248. doi:10.1258/004947506778604706

20. Stübgen J-P. Neuromuscular complications of hepatitis A virus infection and vaccines. J Neurol Sci 2011;300:2-8. doi:10.1016/j.jns.2010.09.015.

21. Bae YJ, Kim KM, Kim KK, Rho JH, Lee HK, Lee YS, et al. A case of acute hepatitis A complicated by Guillain-Barre syndrome. Korean $J$ Hepatol 2007; 13:228-33.

22. Ono S-i, Chida K, Takasu T. Guillain-Barré syndrome following fulminant viral hepatitis A. J Intern Med 1994;33:799-801. doi:10.2169/internalmedicine.33.799.

23. Kuwabara S, Yuki N. Axonal Guillain-Barré syndrome: concepts and controversies. Lancet Neurol 2013;12:11808. doi:10.1016/S1474-4422(13)70215-1.

24. Ho T, Mishu B, Li C, Gao C, Cornblath D, Griffin $\mathrm{J}$, et al. Guillain-Barre syndrome in northern China Relationship to Campylobacter jejuni infection and anti-glycolipid antibodies. Brain 1995;118:597-605. doi:10.1093/brain/118.3.597.

25. Watrin L, Ghawché F, Larre P, Neau J-P, Mathis S, Fournier E. Guillain-Barré syndrome (42 cases) occurring during a Zika virus outbreak in French Polynesia. Medicine 2016;95:e3257.doi:10.1097/ MD.0000000000003257.

26. Van den Berg B, Walgaard C, Drenthen J, Fokke C, Jacobs BC, Van Doorn PA. Guillain-Barré syndrome: pathogenesis, diagnosis, treatment and prognosis. Nat Rev Neurol 2014;10:469-82.doi:10.1038/ nrneurol.2014.121

27. Hiraga A, Mori M, Ogawara K, Hattori T, Kuwabara S. Differences in patterns of progression in demyelinating and axonal Guillain-Barré syndromes. Neurology 2003;61:471-4. doi:10.1212/01. WNL.0000081231.08914.A1.

28. Cosi V, Versino M. Guillain-Barré syndrome. Neurol Sci 2006;27:s47-s51. doi:10.1007/s10072-006-0548-4.

29. Griffin J, Li C, Ho T, Xue P, Macko C, Gao C, et al. Guillain-Barré syndrome in northern China: the spectrum of neuropathological changes in clinically defined cases. Brain 1995;118:577-95. doi:10.1093/ brain/118.3.577.
30. Cheng BC, Chang WN, Chang CS, Chee CY, Huang $\mathrm{CR}$, Chen JB, et al. Guillain-Barré syndrome in southern Taiwan: clinical features, prognostic factors and therapeutic outcomes. Eur J Neurol 2003;10:65562. doi:10.1046/j.1468-1331.2003.00683.x.

31. Kocabas E, Yildizdas D. A child with Guillain-Barre syndrome caused by acute hepatitis a infection. Indian Pediatr 2004;41:92-3.

32. Thapa R, Biswas B, Mallick D, Mukherjee S. Pharyngeal-cervical-brachial variant of pediatric Guillain-Barré syndrome with antecedent acute hepatitis A virus infection. J Child Neurol 2009;24:865-7. doi:10.1177/0883073809332695.

33. Zheng X, Yu L, Xu Q, Gu S, Tang L. Guillain-Barre syndrome caused by hepatitis $\mathrm{E}$ infection: case report and literature review. BMC Infect Dis 2018;18:50. doi:10.1186/s12879-018-2959-2. 